\title{
Electronic student feedback management system based on web development
}

\author{
Fahad Layth Malallah a,1, , Jamal Mahmood a,2, Mahmood Alfathe a,3, Mohammed A. M. \\ Abdullah a,4 \\ ${ }^{a}$ Computer and Information, College of Electronics Engineering, Ninevah University, Mosul, Iraq \\ ${ }^{1}$ fahad.malallah@uoninevah.edu.iq; ${ }^{2}$ jamal1961eng@yahoo.com; ${ }^{3}$ mahmood.alfathe@uoninevah.edu.iq; ${ }^{4}$ \\ mohammed.abdulmuttaleb@uoninevah.edu.iq; \\ * corresponding author
}

\section{ARTICLE INFO}

Article history

Received August 3, 2020

Revised October 13, 2020

Accepted November 20, 2020

Keywords

Client-Server Programming

Database

Electronic Management System

Web-Based Questionnaire

\begin{abstract}
Nowadays, operation management performed by electronic systems in different life sectors is distributed and expanded swiftly due to several advantages that can be achieved, such as time reduction process, simplicity, and high accuracy of running operations. In the educational sector, performing student feedback electrolytically (using PC, Tablet, or Mobile) rather than the ordinary paper-based methods saves staff and students' time and makes managing the data easier. This paper proposes a new approach for the Electronic Student Feedback Management System based on web programming, which consists of input, process, store, and retrieves information using a database. The system is based on the Accreditation Board for Engineering and Technology (ABET) questionnaire model, which is implemented using web development tools (HTML, CSS, Javascript, MySQL, and PHP with Apache web-server). As a result, the proposed system was implemented successfully. The Electronic Engineering College officially adopted it at Ninevah University to perform the student feedback for the academic year 2018-2019, in which 4,282 student feedback applications (SFA) have been recorded. After that, statistical operations were done for extracting useful information effortlessly and accurately. As a result, more than 800 students made 4282 records have participated in the proposed system. This information can be quickly recorded and utilized to identify the weaknesses to address them in the next academic year.
\end{abstract}

This is an open access article under the CC-BY-SA license.

\section{Introduction}

Information technology can have a significant effect on the human way of thinking, as it has entered several parts of human life and also became a significant contributor to making life more manageable and flexible [1]. A web-based application is considered one of these information technologies, which is accessed through the Uniform Resource Locator (URL). In the web-based application, the software is installed at the server-side. Users can access the application from a browser using a URL. The web-based application consists of a web server, which contains all the pages like images, static HTML files, JS. Also, it consists of the application 
server that contains the entire business logic, which is coded using programs like Java. The webbased application also has a database server, which contains entire data stored in the form of tables [2]. The development of performance management became noticeable as a result of the Web service technology integrated with databases and web design. Organizations and cooperation are keen on perfecting operations management of financial and business. Accordingly, web services can increase the performance management system [3]. In terms of questionnaires, paper-based has been considered for a long time for data collection. However, the growing use of the Internet gave new ways of collecting data by using Web-based questionnaires, in which this solution was more cost-effective (by a factor of 10) and had slightly lower numbers of missing values than questionnaires sent with paper invitations [4].

The motivation behind the proposed work is that the online student feedback can give a proper response to the teachers accurately and swiftly. Besides that, it also monitors the students' opinions without providing any manual document or file, as well as the student feedback system can be implemented by using a mobile rather than a personal computer (PC), which has distance flexibility among students of performing the feedback operation to avoid any infecting disease such as the COVID-19 pandemic. The problem of the questionnaire operation based on paper-based usually requires an extensive time to review the collected data, it might contain errors, and unclear information might be in form because the data is written by a human, in addition to being time-consuming [5]. In this paper, a new framework is designed, which consists of web development tools to overcome the aforementioned paper-based questionnaire issues. In other words, web technology with server-client network topology will be used to manage user database resources, or it might be extended to the remote management of database systems.

This paper has six sections organized as follows: Section Two is dedicated to the literature review of previous works. In Section Three, the research methodology design is dully elaborated. Then, Section Four is about experiment implementation. The result and discussion are presented in Section Five. Finally, in Section Six, the conclusion is presented tailed with possible future work.

\section{Method}

\subsection{Literature Review}

The web-page is an application in computer, mobile and tablet software that can be accessed by the "HTTP" protocol (port: 80), and it is classified as in the application layer in TCP/IP protocol. Mainly, two types of scripting web pages, client web-page namely static page that can be constructed using HTML, CSS, and JS, and server-side scripting, namely dynamic web page, can be constructed with one of the server scripting languages such as PHP or ASP, and others.

Recently web-based technology is used in different sectors, one of which is the questionnaire and big data collection from users or customers, due to its simplicity and time reduction properties. A personality questionnaire exploits Web-based as introductory psychology rather than traditional methods as detailed in [6]. Another work is done regarding the comparison between web-based and paper-based, self-administered anthropometric questionnaires [7]. The data collection by using web-based epidemiological studies to reduce the routine processes of the cost and the duration of data processing, the quality of the web-based information was equal or better than that of the paper-based version. In the medical sector, a web-based tool has been designed to facilitate medical student acquisition feedback from surgery residents and faculty. The methodology here is that system-generated data, targeted surveys, and end of clerkship questionnaires were used to evaluate performance over a one-year period where 170 students made 3190 feedback requests [8]. Another form of web-based is related to Universit as Prima Indonesia that has developed and implemented a web-based infrastructure for problem management. In [9], the scenario is done by reporting that the facilities complainant has to meet the responsible person and describe how the problem. After that, the responsible person figures out the problem and submits the solution to the right person. 
The web-based information system has also been exploited in the Tourism sector as in [10], which utilizes a hybrid recommendation filtering for the smart tourism industry. Also used in Web GIS-based public health information systems, which is designed for Japanese Encephalitis (JE) disease outbreaks in the Gorakhpur district, India, as detailed in [11]. A GUI was created using Java Server Pages (JSP) for its customization to benefit GIS and Web technology for public availability in the area for preparation of the health plan. Another related work that employed a web-based client-server technology-supported warehouse management system, as explained in [12], this framework is used to improve the efficiency of the goods storing and retrieving process. Another application used web-based technology for architectural design and modeling a web-based for protecting natural persons with personal data processing and the free movement of such data. A web-based application is constructed to clarify the specific requirements of the Regulation of the European Parliament and the Council [13]. In terms of the educational sector, web-based technology is exploited for Graduation Research conveniently and improves response speed [14]. Also, web-based is used to contain a massive amount of information for a reservoir, including various geological maps, development maps, and surface engineering maps [15]. Web-based has also been used to assess and evaluate examinees' understanding of scientific experiments' procedure, as detailed in [16]. This framework is used multimedia animation to design examination questions and develop a web-based performance assessment system to evaluate examinees' understanding. Finally, in [17], university evaluation has been performed using web-based. The evaluation originated from the Students' satisfaction questionnaire regarding the university infrastructure and so on, to improve the university.

As reviewed in the literature, there is a limited number of works that are specialists in doing web-based questionnaires regarding student feedback management system. Furthermore, a considerable benefit can be obtained to raise the university quality level by providing feedback via a web-based form. Therefore, this paper aims to propose a framework dedicated to generating the database. It can be used for any required result to simplify the management by the university quality assurance administrator.

\subsection{Web-based Services Method}

Web-based service is considered as a computer network at the application layer of TCP/IP protocol [18]. The computer network topology used in this proposed framework is client-server topology.

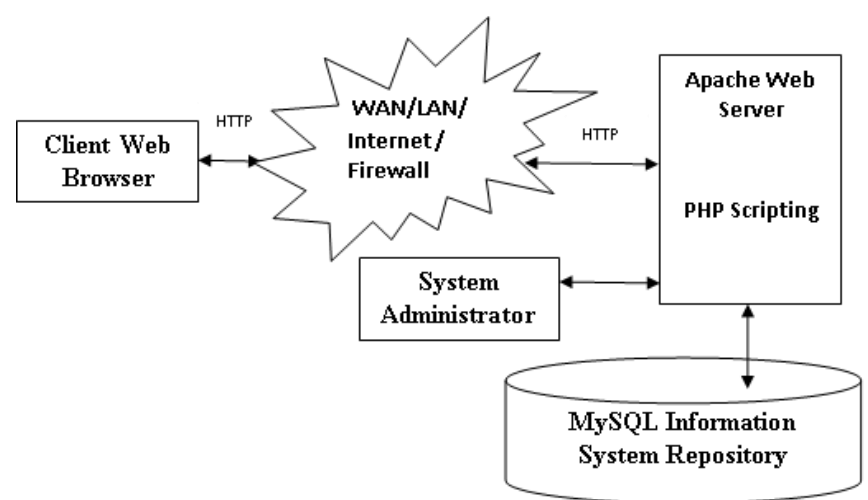

Fig. 1. Proposed Client-server web-based management system architecture

Users or customers who are required to give their feedback are considered clients (using a smartphone, tablet, laptop), while the feedback points are all being collected at the server-side. In terms of the construction, the client-side is built using the following web programming tools like HTML, CSS, and JS, while the server PHP scripting program is used on the server-side. The web server is also used in this work under the Apache web server, and the database server environment is used called MySQL for building databases and tables [19]. The overall block diagram in Fig. 1 depicts the proposed framework. In other words, it means that the end-user can either give his/her feedback comments by computer or mobile. In mobile, a wireless access point must be connected to the network to provide a connection to the mobile to add more 
flexibility for users regarding the questionnaire. Afterward, as in Fig. 2, the proposed workflow diagram is divided into two parts.

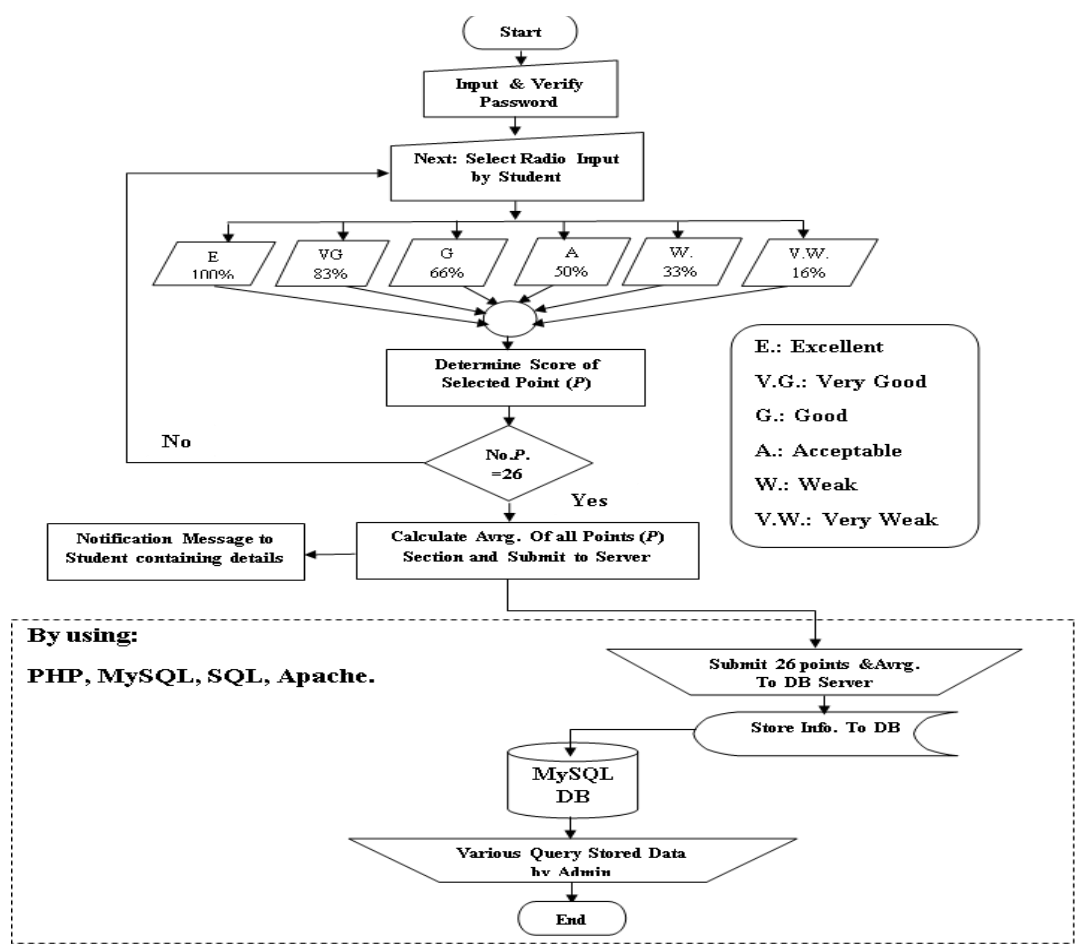

Fig. 2. Workflow illustrates the proposed student feedback score computing, submission, and database

The first one is related to the client-side scripting and construction, while the second part is regarding submitting and receiving the feedback and server-side scripting. The scenario is kicked off by keying in the password for security issues as this operation is authorized only to the targeted group of students and not to anyone else. Once the credential is satisfied, the student will read and give his/her feedback on the main six points, as each point is expressed as a question alone. Each point must be evaluated according to these six categories as follows: Excellent, V. Good, Good, Acceptable, weak, and very weak, which are translated to numerical scoring as in (1).

$$
\operatorname{Score}(p)=\frac{100}{6} \times R
$$

The $\mathrm{R}$ refers to Radio input types, as elaborated in Table 1.

Table 1. Description of dataset

\begin{tabular}{ccccccc}
\hline Evaluation Type & Excellent & Very Good & Good & Acceptable & Weak & Very Weak \\
\hline $\mathrm{R}$ & 6 & 5 & 4 & 3 & 2 & 1 \\
\hline
\end{tabular}

After completing all the 26 points (based on ABET questions) for a student, the average will be computed at the client-side using JavaScript. Moreover, together, all the 26 points and the average with the date will be submitted from the client-side to the server-side to be stored in the database to conduct further operations. Next, another student's information will be submitted to the database, and so on. In terms of the web development tools used in this research, HTML, CSS, and JS are used for the client-side, while PHP, MySQL [20], and Apache web server are used. Here, PHP's task is to implement SQL operations such as insert, delete, select, and others.

The next subsection will be dedicated to describing both front-end (client-side) and the back-end (server-side) in detail. 


\subsection{Front-End (Client-Side)}

In the beginning, the first step to being performed by the student is entering the credential for the authentication manner and making sure that this student is suitable for this evaluation type, as illustrated in Fig. 3. Besides, this operation will prevent the same student from repeating the questionnaire more than once not to affect the data correctness.

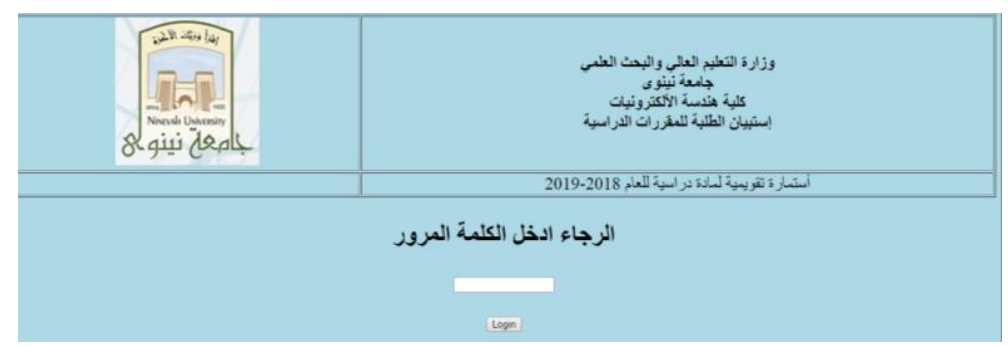

Fig. 3.The client-side in which security credentials are entered

Table 2. Questionnaire items containing 26 points in both Arabic and English languages

\begin{tabular}{|c|c|c|c|c|c|c|c|c|}
\hline \multicolumn{6}{|c|}{ Evaluation } & Arabic Question & \multicolumn{2}{|l|}{ English Question Good } \\
\hline مشتر & ابل جنا & با & مأبيرل & ضغبذ & 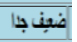 & ت إترات الأسنبيان & Questions & No. \\
\hline a & & & 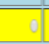 & 0 & 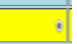 & 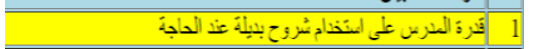 & $\begin{array}{l}\text { Lecturer's ability to present alternative explanations } \\
\text { when needed }\end{array}$ & 1 \\
\hline$=$ & & & to & $\cdot$ & & 2 & $\begin{array}{l}\text { Class discussion and Homework } \\
\end{array}$ & 2 \\
\hline 0 & & & $\cdot$ & 0 & & 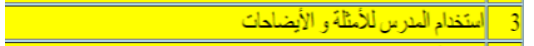 & Lecturer's use of examples and illustrations & 3 \\
\hline$=$ & & : & of & 0 & & 4 & Explanation by lecturer & 4 \\
\hline 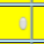 & $\cdot$ & & & (1) & & 5 & Use of class time & 5 \\
\hline$\cdot$ & 0 & 0 & 0 & 0 & & 6 كاس المدري & Lecturer enthusiasm & 6 \\
\hline$\cdot$ & 0 & o & $=$ & $=1$ & & 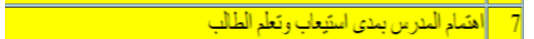 & Lecturer's interest in whether students learned & 7 \\
\hline 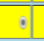 & (1) & 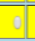 & $=$ & 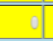 & & 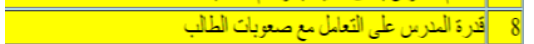 & Lecturer's ability to deal with students difficulties & 8 \\
\hline$\cdot$ & 0 & o & 0 & 0 & & 9 & Students confidence in lecturer's knowledge & 9 \\
\hline$\cdot$ & 0 & 0 & 0 & 0 & & 10 تحضير المزرس المداضر ات & Lecturer's preparation for class & 10 \\
\hline 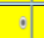 & 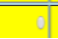 & 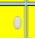 & (1) & 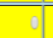 & 7 & 11 كناعة المبرس في تكريس المادة & Lecturer's effectiveness in teaching the subject matter & 11 \\
\hline$\cdot$ & 0 & $\bullet$ & $\bullet$ & $\cdot$ & 0 & 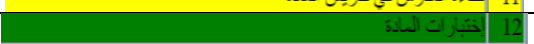 & Course Examinations & $\mathbf{n}$ \\
\hline$\cdot$ & 0 & $\bullet$ & ○ & $\bullet$ & 0 & 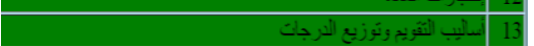 & Evaluation and grading techniques & 13 \\
\hline$=$ & $\cdot$ & 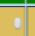 & 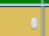 & $\overline{0}$ & 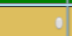 & 14 إبات المدرس على أسلة الطلبة & Lecturer's answers to the students questions & 14 \\
\hline - & . & 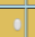 & 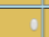 & + & 0 & 15 | إحتر ام المدرس لأراء الطلب & Lecturer's respect for students views & 15 \\
\hline 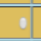 & $\cdot$ & 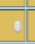 & 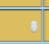 & + & 0 & 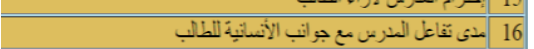 & Lecturer's consideration of student humanitarian & 16 \\
\hline 0 & 0 & 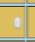 & : & + & ] & 17 إلتزز ام المدرس بوقتَ الحضور الَى المداضرة & \begin{tabular}{|l|} 
problems \\
Lecturer's record for coming to class on time \\
\end{tabular} & 17 \\
\hline 0 & $\cdot$ & 0 & 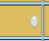 & 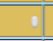 & 0 & 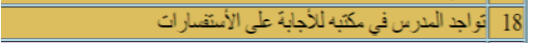 & Lecturer's availability for extro heip & 28 \\
\hline 0 & $\cdot$ & 0 & 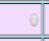 & 0 & 可 & 19 & The course content & 19 \\
\hline 0 & 0 & $\cdot$ & 0 & 0 & & 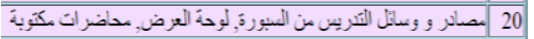 & Teaching materials and resources & 20 \\
\hline 0 & $\cdot$ & 0 & (1) & 0 & & 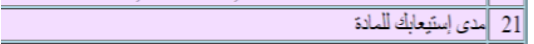 & Leaming feedback & 21 \\
\hline 0 & 0 & 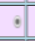 & 0 & 0 & & 22 |مدى إرنباط مغردات المادة & Relevance and usefuiness of course content & 2 \\
\hline 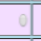 & 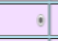 & 0 & 0 & 0 & & 23 سمستو انجذابك في المداضرات & interesting level of class session & 23 \\
\hline 0 & $\cdot$ & 0 & 0 & (1) & & 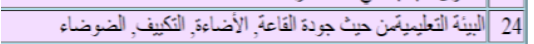 & Learning environment & 24 \\
\hline 0 & $\cdot 1$ & 0 & 0 & 0 & & 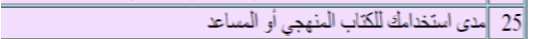 & Usefulness of reference books & 25 \\
\hline of & 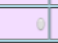 & $\cdot$ & 0 & 0 & 0 & 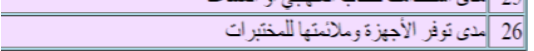 & avaliability of laboratory equipments & 26 \\
\hline
\end{tabular}

After that, the student must only give some details such as the department, level of the study, name of the lecturer, and the lecture subject name, which are designed by using a drop-down list for adding simplicity as depicted in Fig. 4. The proposed system granted all these previous entries required critical conditions. After that,26 points will appear as illustrated in Table 2, which is reported in Arabic and English, each with its evaluation. Moreover, this form is appearing precisely to the students during performing questionnaire operation. Also, as it is clear from Table 2, there are six types of radio-input selection for each point, the better one is excellent, and the worst one is weak.

Regarding the nature of these questions, which are designed according to ABET (Accreditation Board for Engineering and Technology), 26 questions are divided into four subsections. Each one is expressed on a specific meaning, such as the first 11 points are designed to show the lecturer's ability on the lecture being delivered to the students. The points 12-13 are related to exams and evaluation correctness, and the 14 till 18 reflect the academic relationship 
between the lecturer and the students. Finally, 19 to 26 are used to assess the lecture suitability for the students. It is preferable to give an exact result of the weaknesses and the power of lecturers, and the overall average is weighted according to 11,2,5,8 question points.

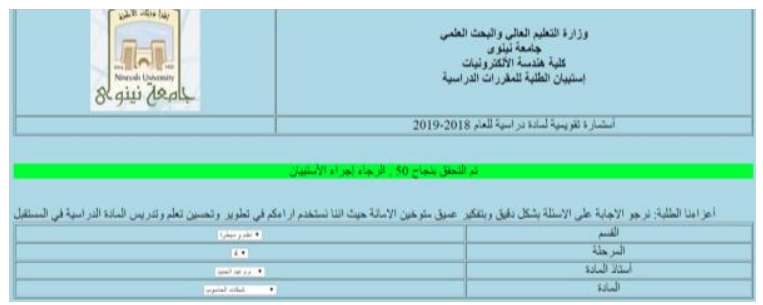

Fig. 4.The front panel of the feedback management system

Furthermore, the proposed framework can gather all the information in a small space (at the page tail). It is reviewed by the student quickly before submission to the server as in Fig. 5, which depicts an instance result of selected radio-input and waiting for the next step of pressing send information.

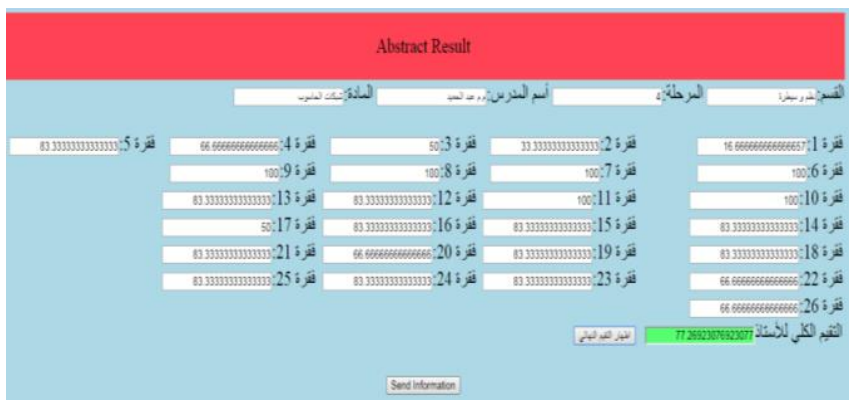

Fig. 5. Final confirmation window to be submitted to the database

Finally, once the student submitted the information in Fig. 5 to the server, a status message appears to the student to inform whether a successful or failed submission occurred. In case of successful status, detailed information will be appeared containing the calculated score, date, general information for confirmation as in Fig. 6 as an example.

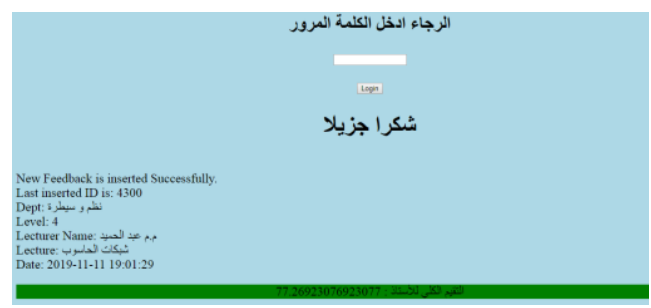

Fig. 6. Final confirmation window informing the student of the successful submission

\subsection{Back-End (Server-Side)}

On the server-side, a database is created named 'questionnaire', inside the database; two tables are created and required in this design, which are:'feedback' and 'password'. The utilized database environment is entitledMySQL, which is built-in phpMyAdmin, as shown in Fig. 7.

The Table 'feedback' is considered the information dump used to store all the submitted data. This table has been designed to contain 33 fields (columns). Each field specification is as follows: the fields 1 till 5 are for ID, dept, level, lecturer_name, and lecture, respectively, as shown in Fig. 7, while the fields 6 till 31 are dedicated to the 26 questions ques_1 till ques_26respectively. Finally, fields 32 and 33 are for the average of the 26 questions out of $100 \%$ and the date of submission, respectively. Moreover, the details and attributes for each field are available correspondingly in Fig. 7 as well. 


\section{Results and Discussion}

On the test of the proposed framework, this management system has been considered officially by the Electronic Engineering college-Ninevah University for conducting student feedback for their students in the academic year 2018-2019. The college has four departments: communication, computer and information, system and control, and electronic. The result of this proposed work depends on the quality assurance for the lecturer evaluation.

The feedback has been conducted at the computer and information department building at Network Laboratory, which has around 30 PC connected in a LAN network. Furthermore, if students are more than 30 , they could use their mobile phones to connect to the Wi-Fi network. It is connected to the LAN and can access the HTTPS link (URL is given to students at the time of evaluation) and password to login to the questionnaire system and submit their opinion remotely by Mobile phone.

The operation of collecting student feedback has continued for around eight days to ensure that all students and departments can participate in this questionnaire. They express opinions freely to allow the university to improve factors that have been noticed weak. It is worth mentioning that cooperating with the college's quality assurance department, nine lecturers and technicians were participated to supervise this operation to ensure the questionnaire's smooth running.

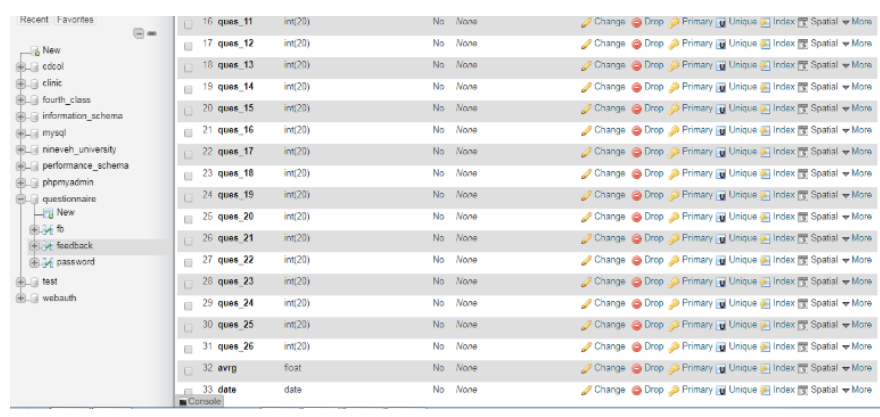

Fig. 7.The questionnaire database, tables, and field attributes

The main table used to store the data in the proposed system is called "feedback", which contains 33 fields, each explained with its attributes as illustrated in Fig. 7.

The proposed student feedback management system has stored 4,282 records, as shown in Fig. 8 as the number of rows. These rows are considered student feedback applications for the four departments and all levels (1-4). Each record in the 'feedback' table contains 33 fields, as explained in the previous section.

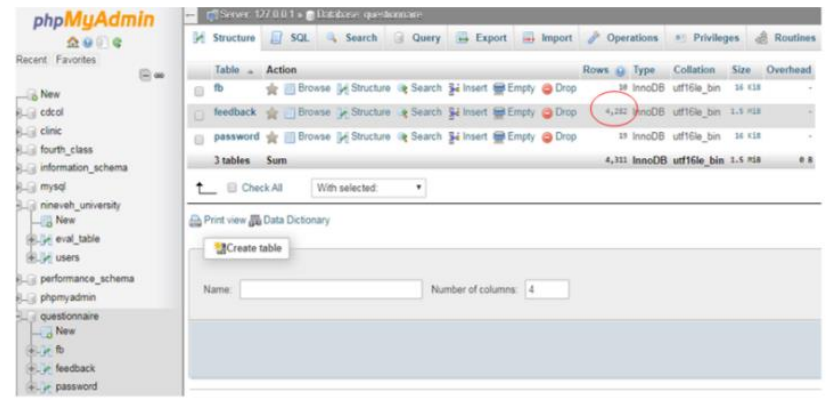

Fig. 8. The questionnaire database, tables, and field attributes with 4,282 records student feedback stored

In Fig. 9.(a), it is clear that the stored information for each record has the panned information, for instance, ID 4274, dept 'الكترونيك' level '4' lecturer_name 'xxxx' and ques_1 is 33, ques_2 is 33, ques_3 is 50 and so on until ques_33 then storing the average and the date submission as shown in Fig. 9.(b). 


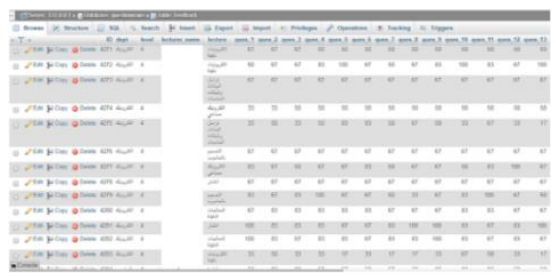

(a)

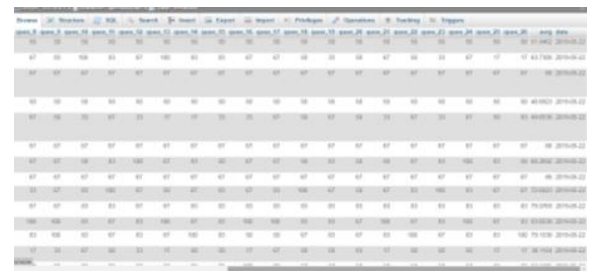

(b)

Fig. 9. (a) Data type stored in (b) each record

As part of the result, the records have been filtered for each department to extract the feedback's average score shown in Fig. 10.(a). This graph shows all students who have given feedback to the communication department. In contrast, in Fig. 10.(b) the student in the electronic department, and Fig. 10.(c) the score of the system and control department, and finally in Fig. 10.(d) illustrates the students who have given a score for the computer \& information department. Here the exact score percentage is not precise in this graph. However, it gives some indication where are the majority of the scores ranging from $0 \sim 100 \%$.

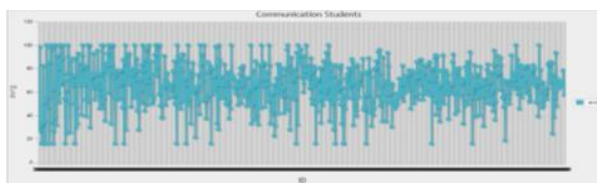

(a)

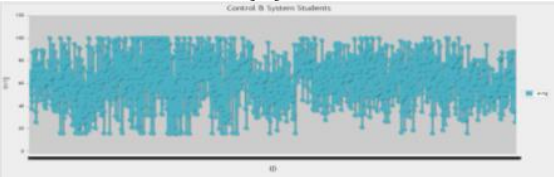

(a)

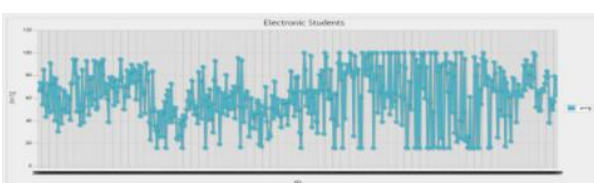

(b)

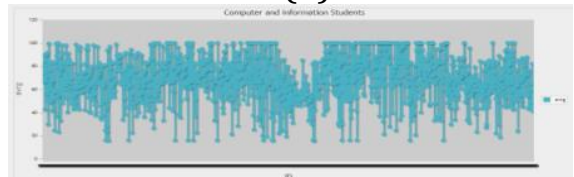

(b)

Fig. 10. Average score for all student feedback applications per department

The number of feedback applications registered for each department is illustrated in Table 3 , as it is noticed that numbers of applications in the database are as following 782, 1306, 1721, 473 applications for the following departments: Communication, Computer \& Information, System \& Control, and Electronics respectively. Overall, applications that have been recorded are 4282. Simultaneously, the numbers of applications are not similar among the four departments, due to the different number of lectures for each department and the different number of student-related to each department.

Table 3. The number of students who participated in each department

\begin{tabular}{ccc}
\hline No & Department & Number of Students participated \\
\hline 1 & Communication & 782 \\
\hline 2 & Computer \& information & 1306 \\
\hline 3 & System \& control & 1721 \\
\hline 4 & Electronics & 473 \\
\hline & All & 4282 \\
\hline
\end{tabular}

Password will be added to the login web page to prevent any student from repeating the questionnaire operation more than once. The password will be reset from time to time to prevent the outside user or any intruder from illegally doing the questionnaire. The table named "password' is shown in Fig. 11. It has the fields as "ID_p" and the "number" which the password and the "date" of the password resetting. It is worth mentioning that the proposed methodology is much suitable for the LAN network, which might be a limitation. However, suppose it is required to be generalized for using the Internet. In that case, security issues are required to be added to the proposed idea. It ensures the correctness of the stored information in terms of confidentiality, availability, and integrity of the system. Also, the constructed Mysql database is 
not relational because only two tables are used in the proposed system without connecting to them. Here, the comparison with the state-of-the-art is illustrated in Table 4.

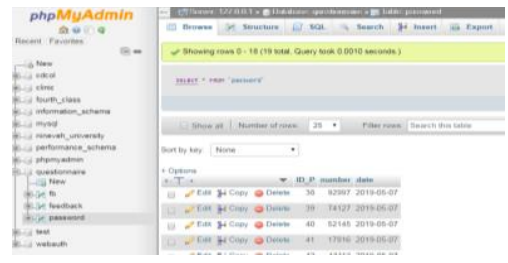

Fig. 11. The 'password' table used to store the password

Table 4. State-of-the-art comparison

\begin{tabular}{|c|c|c|c|c|}
\hline Web Type & Web Structure & Storing Info & Year/Ref. & $\begin{array}{c}\text { Time } \\
\text { Collecting }\end{array}$ \\
\hline $\begin{array}{c}\text { Feedback from } \\
\text { Medical students }\end{array}$ & Client-server web & $\begin{array}{c}170 \text { students made } \\
3190 \text { feedback requests }\end{array}$ & $2018 /[8]$ & One-year \\
\hline $\begin{array}{l}\text { Graduation Research } \\
\text { conveniently }\end{array}$ & $\begin{array}{c}\text {-Client-side: Visual DOM as } \\
\text { javascript by using React.js } \\
\text {-Server-side: Node.js \& } \\
\text { MongoDB }\end{array}$ & $\begin{array}{l}\text { Time as hours spent by } \\
\text { students in the } \\
\text { laboratory for research }\end{array}$ & $2018 /[14]$ & One-year \\
\hline $\begin{array}{c}\text { Evaluating } \\
\text { examinee's } \\
\text { understanding }\end{array}$ & $\begin{array}{c}\text { Client-side: HTML, CSS , } \\
\text { Javascript, Server-side: PHP } \\
\text { \& XML }\end{array}$ & $\begin{array}{c}\text { multimedia animation } \\
\text { questions }\end{array}$ & $2018 /[16]$ & - \\
\hline $\begin{array}{c}\text { Performing } \\
\text { students } \\
\text { questionnaires }\end{array}$ & $\begin{array}{c}\text { Client:side:HTML, CSS, JS. } \\
\text { Server-side:PHP, Mysql, } \\
\text { Apatchi }\end{array}$ & $\begin{array}{c}\text { More than } 800 \\
\text { students made } 4282 \\
\text { records }\end{array}$ & Proposed & One month \\
\hline
\end{tabular}

\section{Conclusion}

A proposed framework for student feedback web-based was designed and implemented successfully using web development tools. The implementation recorded 4282 records, as each record represents a student application. This framework has a positive impact on the management's progressing in terms of handling the feedback application. It can do processes while storing and retrieving useful information more efficiently than ordinary paper-based feedback. In addition to its accuracy, it is superior to the paper-based as it is free of errors and others. Besides, this idea's advantage is that the student might use a mobile phone to do the questionnaire rather than a PC, which has the advantages of achieving the social distance required to avoid any infected disease such as the pandemic Covid-19. In future work for simplicity, the proposed framework might be connected with the university website, to be logged in remotely via the Internet. As a result, the student can do the questionnaire via the Internet much more comfortable.

\section{References}

[1] A. M. A. FarajAllah, S. A. El Talla, S. S. Abu-Naser, and M. J. Al Shobaki, "The impact of technological and human requirements for re-engineering processes in improving productivity," Int. J. Acad. Inf. Syst. Res., vol. 2, no. 9, pp. 29-38, 2018, [Online]. Available: http://dstore.alazhar.edu.ps/xmlui/bitstream/handle/123456789/160/IJAISR180903.pdf?seque nce=1\&isAllowed $=y$.

[2] R. Connolly, Fundamentals of web development. Pearson Education. 2015. Available: Google Scholar.

[3] B. Chen, "Research of performance management system based on web services," in 2018 3rd International Workshop on Materials Engineering and Computer Sciences (IWMECS 2018), 2018, pp. 221-225, [Online]. Available: https://www.atlantis-press.com/article/25893510.pdf.

[4] J. F. Ebert, L. Huibers, B. Christensen, and M. B. Christensen, "Paper- or web-based questionnaire invitations as a method for data collection: cross-sectional comparative study of differences in response rate, completeness of data, and financial cost," J. Med. Internet Res., vol. 20, no. 1, p. e24, 
Jan. 2018, doi: 10.2196/jmir.8353.

[5] G. Priyanka, B. Purva, P. Sneha, and G. M. Lodha, "Survey paper on web based student feedback system," Recent Trends Androids IOS Appl., vol. 1, no. 2, 2019. Available: Google Scholar.

[6] R. N. Davis, "Web-based administration of a personality questionnaire: Comparison with traditional methods," Behav. Res. Methods, Instruments, Comput., vol. 31, no. 4, pp. 572-577, Dec. 1999, doi: 10.3758/BF03200737.

[7] M. Touvier et al., "Comparison between web-based and paper versions of a self-administered anthropometric questionnaire," Eur. J. Epidemiol., vol. 25, no. 5, pp. 287-296, May 2010, doi: 10.1007/s10654-010-9433-9.

[8] P. E. Georgoff et al., "Evaluating the performance of the Minute Feedback System : A web-based feedback tool for medical students," Am. J. Surg., vol. 215, no. 2, pp. 293-297, Feb. 2018, doi: 10.1016/j.amjsurg.2017.08.047.

[9] R. WijayaDewantoro, S. Wardani, Rudy, B. S. Perdana Girsang, and A. Dharma, "Development and implementation of web based infrastructure for problem management at UNPRI," J. Phys. Conf. Ser., vol. 1007, p. 012052, Apr. 2018, doi: 10.1088/1742-6596/1007/1/012052.

[10] R. Hassannia, A. Vatankhah Barenji, Z. Li, and H. Alipour, "Web-based recommendation system for smart tourism: multiagent technology," Sustainability, vol. 11, no. 2, p. 323, Jan. 2019, doi: $10.3390 /$ su11020323.

[11] S. Verma, "Development of Web GIS Based Framework for Public Health Management System Using ERDAS Apollo 2010," in Healthcare Policy and Reform, IGI Global, 2019, pp. 239-253, doi: 10.4018/978-1-5225-1814-3.ch005.

[12] J. Yu and J. Xu, "Design and implementation of warehouse management system based on web technology," in 20183 rd International Conference on Mechanical, Control and Computer Engineering (ICMCCE), Sep. 2018, pp. 665-671, doi: 10.1109/ICMCCE.2018.00147.

[13] R. Romansky and K. Kirilov, "Architectural design and modelling of a web based application for GDPR clarification," in AIP Conference Proceedings, 2018, vol. 2048, no. 1, p. 060006, doi: $10.1063 / 1.5082121$.

[14] Z. Xu and B. Ni, "Graduation research management system developed by recent web technology," in 2018 International Conference on Engineering, Applied Sciences, and Technology (ICEAST), Jul. 2018, pp. 1-3, doi: 10.1109/ICEAST.2018.8434478.

[15] G. Lin, “Design and Development of Reservoir Dynamic Analysis System Based on Web," in 2019 International Conference on Communications, Information System and Computer Engineering (CISCE), Jul. 2019, pp. 106-108, doi: 10.1109/CISCE.2019.00031.

[16] T.-H. Wang, "Developing a web-based assessment system for evaluating examinee's understanding of the procedure of scientific experiments," EURASIA J. Math. Sci. Technol. Educ., vol. 14, no. 5, pp. 1791-1801, Feb. 2018, doi: 10.29333/ejmste/85170.

[17] F. L. Malallah, M. G. Saied, M. T. Alasaady, and B. T. Shareef, "Internet of things: Web-based questionnaire for university evaluation," Sci. J. Cihan Univ. - Slemani, vol. 3, no. 2, pp. 26-44, 2019, [Online]. Available: https://sj.sulicihan.edu.krd/files/2020/03/26-44.pdf.

[18] M. B. Yassein, M. Q. Shatnawi, and D. Al-zoubi, "Application layer protocols for the Internet of Things: A survey," in 2016 International Conference on Engineering \& MIS (ICEMIS), Sep. 2016, pp. 1-4, doi: 10.1109/ICEMIS.2016.7745303.

[19] S. Sunardi, A. Fadlil, F. Al-anshori, and S. Saifullah, "Information system development based-on ERP and RAD methods: Application for activities information broadcasting," JUITA J. Inform., vol. 8, no. 2, p. 149, Nov. 2020, doi: 10.30595/juita.v8i2.7684.

[20] A. T. Hidayat, A. M. D. Dewantara, and S. Saifullah, "The Development of Website on Management Information System for E-commerce and Services," J. Sisfokom (Sistem Inf. dan Komputer), vol. 9, no. 3, pp. 380-386, Oct. 2020, doi: 10.32736/sisfokom.v9i3.992. 